\title{
Renin-angiotensin system blockade: Effect on renal mRNA expression in 5/6 nephrectomized rats
}

\author{
Erika Yadira Cruz-Laguna ${ }^{1}$, Ana Ma. Gámez-Méndez ${ }^{2}$, Hilda Vargas-Robles ${ }^{2}$, Amelia Ríos $^{3}$, \\ Alfonso Méndez-Tenorio ${ }^{1}$, Bruno Escalante ${ }^{3^{*}}$ \\ ${ }^{1}$ Laboratorio de Biotecnología y Bioinformática Genómica, Escuela Nacional de Ciencias Biológicas (IPN), México City, México \\ ${ }^{2}$ Departamento de Biomedicina, CINVESTAV Unidad Zacatenco, México City, México \\ ${ }^{3}$ CINVESTAV Unidad Monterrey, Apodaca, México; ${ }^{*}$ Corresponding Author: bescalan@ cinvestav.mx
}

Received 25 February 2013; revised 27 March 2013; accepted 3 April 2013

Copyright (C) 2013 Erika Yadira Cruz-Laguna et al. This is an open access article distributed under the Creative Commons Attribution License, which permits unrestricted use, distribution, and reproduction in any medium, provided the original work is properly cited.

\section{ABSTRACT}

The aim of this study was to determinate the gene expression levels of angiotensinogen, angiotensin converting enzyme, renin, (pro)renin receptor, and the final rennin-angiotensin system (RAS) products Angiotensin (Ang) II and Ang 1-7 in the remnant kidney of 5/6 nephrectomized rats and its response to RAS pharmacological blockade. Male Wistar rats were divided into five groups: sham operated (SO), 5/6 nephrectomized (NFX), NFX + captopril (50 mgl $\mathrm{kg} /$ day), NFX + losartan (10 $\mathrm{mg} / \mathrm{kg} /$ day), and NFX + aliskiren (10 mg/kg/day). Animals were followed up for 60 days and protein urine excretion was measured. Systolic blood pressure, renal tissue RAS mRNA expression levels, plasma Ang II, and plasma Ang 1-7 were evaluated at day 60 after nephrectomy. Blood pressure and urine protein were increased after $5 / 6$ nephrectomy. Ang II levels were increased 9.4 fold, whereas Ang 1-7 decreased $72.9 \%$ in NFX animals compared with SO rats. 5/6 nephrectomy increased renal angiotensinogen and (pro)renin receptor mRNA expression but down-regulated renin MRNA expression. RAS blockade restored the systolic blood pressure to normal values and slowed down urinary protein excretion, and also prevented changes in Ang II and Ang 1-7. RAS blockade reduced (pro)renin receptor, ACE, and AGT mRNA expression in the remnant kidney. However, renin mRNA expression increased compared with NFX rats. In conclusion these results suggest that inhibition of Ang II synthesis by RAS blockade is associated with renal regulation of RAS mRNA expression and this may be through a mechanism related with the
Ang II/Ang 1-7 balance.

Keywords: Angiotensin II; Angiotensin 1-7; ACE; RAS Blockade

\section{INTRODUCTION}

The Renin Angiotensin System (RAS) is one of the most phylogenetically conserved hormonal systems among vertebrates [1], and is recognized as a system that interacts in endocrine, paracrine, autocrine, and intracrine way. This protein cascade is involved on adrenal, cardiovascular, and renal functions that regulate fluid and electrolyte balance, and has a pivotal role on the control of arterial pressure. Increased activation of RAS participates in several pathological processes including hypertension [2]. The classical RAS begins with the cleavage of angiotensinogen (AGT) by renin (REN) to form the decapeptide angiotensin (Ang) I. Ang I is hydrolyzed by the action of the angiotensin converting enzyme (ACE) and the product Ang II is the major biologically active peptide of RAS. Ang II biological responses are mediated by the Ang II Type $1\left(\mathrm{AT}_{1}\right)$ or Type $2\left(\mathrm{AT}_{2}\right)$ receptors [3]. However, in the last years new insights have been added to the knowledge of RAS. The recognition of tissue RAS, the description of new biologically active peptides besides Ang II, new enzymes along with new functional receptors involved in RAS have been reported [4,5]. Additionally, the recent description of a (pro)REN receptor $[(\mathrm{P}) \mathrm{RR}]$ which triggers biological pathways and the activation of (pro)REN when bound to this receptor have contributed to switching our understanding of RAS [6]. Furthermore, several RAS metabolites may be responsible for changes in RAS protein and mRNA expression. It has been demonstrated that RAS intermediaries or mRNA expression are increased during several pathophysiological conditions [2,3]. During RAS pharmacol- 
ogical blockade the concentration of RAS metabolites is altered and this may be associated with changes in the RAS mRNA expression. Studies have shown that Ang II up-regulates AGT mRNA through nuclear factor-kappa $\mathrm{B}$ activation [7]. Ang II also regulates REN metabolism, in vitro studies have suggested that REN synthesis in collecting ducts can be directly increased by Ang II [8], and this increment in REN synthesis may be mediated by the $\mathrm{AT}_{1}$ receptor, independently of blood pressure $[9,10]$. Down regulation of ACE was showed in adipose tissue, suggesting that reduction in ACE transcription is related with decreased Ang I $[2,11]$. Thus, the study of RAS mRNA expression and the response to its pharmacological blockade may be the key to understand its significance on the therapeutic response. Therefore, the aim of this study was to test the effect of pharmacological RAS modulation on mRNA expression of the different proteins involved in RAS metabolic pathway. Since pharmacological RAS blockade may lead to different metabolite accumulation/change, we used in this study drugs that affect 3 different steps of RAS. 5/6 nephrectomy is a method associated with hypertension and RAS activation, thus we used several RAS blockade strategies on $5 / 6$ nephrectomized rats to compare changes on mRNA expression of the major RAS components and on the final RAS products Ang II and Ang 1-7.

\section{MATERIALS AND METHODS}

\subsection{Animal Model}

All animal procedures were conducted in accordance with Federal Regulations for animal experimentation and Care and were approved by the Animal Care Committee of CINVESTAV (CINVESTAV Zacatenco, D.F., México). Two months old male Wistar rats were housed in humidity and temperature controlled room with a 12-h light/ dark cycle. Rats were fed with a regular diet (LabDiet, USA) and had free access to tap water. The 5/6 nephrectomy was achieved by removal of the right kidney and infarction of two thirds of the left kidney as previously reported [12]. Briefly, after sodium pentobarbital anesthesia (40 mg/Kg, ip) $5 / 6$ nephrectomized (NFX) animals were obtained after ablation of the right kidney and selective ligation of two branches of the renal artery, which produced infarction of approximately two thirds of the left kidney. Sham operated rats (SO) were anesthetized and kidneys were exposed without performing nephrectomy or renal artery ligation, these animals were used as control group. Rats were randomly allocated in five groups: 1) $\mathrm{SO}(\mathrm{n}=5)$; 2) NFX $(\mathrm{n}=5)$; 3$)$ NFX treated with captopril, $50 \mathrm{mg} \cdot \mathrm{Kg}^{-1} \cdot \mathrm{day}^{-1}(\mathrm{NFX}+\mathrm{CAP}, \mathrm{n}=5)$; 4) NFX treated with losartan, $10 \mathrm{mg} \cdot \mathrm{Kg}^{-1} \cdot \mathrm{day}^{-1}$ (NFX + LOS, $\mathrm{n}$ = 5); 5) NFX treated with aliskiren, $10 \mathrm{mg} \cdot \mathrm{Kg}^{-1} \cdot \mathrm{day}^{-1}$ (NFX + ALIS). Drugs doses were selected as reported and administrated by gavage, animals were followed-up for 60 days. Measurement of urinary protein excretion and systolic blood pressure (SBP) were used to evaluate the impact of 5/6 nephrectomy on renal function.

\subsection{Urinary Protein Excretion}

Rats were housed on metabolic cages 3 days prior urine collection. Consumed water and urine volume of 24 hours were measured. The urine was collected 14, 28, 42 , and 56 days after surgery. Total protein was determined according to Bradford's method [13].

\subsection{Systolic Blood Pressure Measurement}

At day 60 after surgery, blood pressure was measured by carotid artery cannulation as previously reported [14], using a heparinized Tygon ${ }^{\circledR}$ catheter (Baxter Diagnostics, McGann Park, IL, USA) attached to a solid-state pressure transducer system (WPI, Sarasota, FL, USA). After a 10 min equilibration period, SBP was measured for 10 min with DUO v2.0 software (WPI, Sarasota, FL, USA); readings were taken every $2 \mathrm{~min}$ and recorded for later analysis.

\subsection{Collection of Blood Plasma and Renal Tissue}

After SBP was obtained, blood was collected on tubes with EDTA (Vacutainer ${ }^{\mathbb{R}}$ ) and centrifuged at $3000 \mathrm{~g}$ for 10 minutes at room temperature; plasma was stored at $-70^{\circ} \mathrm{C}$. Kidneys were removed and immediately frozen in liquid nitrogen and stored at $-70^{\circ} \mathrm{C}$ for subsequent use.

\subsection{Plasma Ang II and Ang 1-7 Determination}

Simultaneous detection and quantification of Ang II and Ang 1-7 were performed by capillary zone electrophoresis with UV detection by photodiode-array (CZEPDA) [15]. Briefly, plasma was deproteinized with methanol (10:1), homogenized, and centrifuged at $16,000 \mathrm{~g}$ for 15 min at $4^{\circ} \mathrm{C}$. Pellet was discarded and supernatant was deproteinized by the addition of $20 \%$ trichloroacetic acid, homogenized, and centrifuged at $16,000 \mathrm{~g}$ for $15 \mathrm{~min}$ at $4^{\circ} \mathrm{C}$. Supernatant was filtered through a $0.22 \mu \mathrm{m}$ nitrocellulose membrane filters (Millipore, USA) and diluted 1:10 with $0.1 \mathrm{M} \mathrm{NaOH}$. Then, the sample $(2 \mathrm{~mL})$ was passed through a Sep-Pak Classic C-18 cartridge (Waters Corporation, USA). Simultaneous detection and quantification of Ang II and Ang 1-7 by CZE-PDA analysis was performed with $100 \mu \mathrm{L}$ of each sample using a Beckman Coulter (Fullerton, USA) P/ACETM MDQ Capillary Electrophoresis System equipped with PDA and controlled by means of the P/ACEMDQ Capillary Electrophoresis System software version 7.0 (Beckman Coulter Inc., USA). 


\subsection{Quantitative RT-PCR}

Total RNA was extracted from the kidneys using TRIZOL reagent (Invitrogen, USA), $5 \mu \mathrm{g}$ of total RNA was reverse transcribed into cDNA in a total reaction mixture volume of $20 \mu \mathrm{L}$ using the MMLV reverse transcriptase (Invitrogen, USA) according to the manufacturer's instructions. To perform the real time quantitative PCR (Q-PCR) we used commercially available gene expression assays (Taqman $^{\circledR}$, Applied Biosystems ${ }^{\mathrm{TM}}$, USA) for AGT (Rn00593114 m1), REN (Rn00561847 m1), ACE (Rn00561094_m1), (pro)REN receptor (ATP6ap2, Rn01430718_m1), and 18S rRNA as endogenous control. Amplification was performed using the StepOne ${ }^{\mathrm{TM}}$ RealTime PCR system (Applied Biosystem ${ }^{\mathrm{TM}}$ ). Q-PCR protocol was set up according to the manufacturer's instructions. Each mRNA target was relative quantified by measuring the threshold cycle. Analysis of relative gene expression was performed using the $\Delta \Delta \mathrm{CT}$ method [16]. Each sample was run in triplicate with co-amplification of target and endogenous genes. The samples from the SO animals were used as reference.

\subsection{Statistical Analysis}

Comparisons among the different treated groups were analyzed by ANOVA followed by Newman-Keuls test. Data are expressed as mean $\pm \mathrm{SEM}, \mathrm{p}<0.05$ was defined as statistically significant.

\section{RESULTS}

\subsection{RAS Blockade Effect on Renal Functional Parameters}

As we previously showed [17], 14 days after 5/6 nephrectomy urinary protein excretion was increased from $32.2 \pm 5.8$ to $102.84 \pm 37.32 \mathrm{mg} / 24 \mathrm{~h}(\mathrm{p}=0.001)$, this effect persisted for the following 6 weeks (Figure 1(a)). Also SBP was increased from $112.6 \pm 12.5 \mathrm{mmHg}$ to $191.8 \pm 12.7 \mathrm{mmHg}$ compared with $\mathrm{SO}$ rats, 60 days after $5 / 6$ nephrectomy $(\mathrm{p}<0.001)$. As expected and regardless the step of the RAS metabolic pathway targeted, RAS blockade in NFX rats treated with captopril (ACE inhibitor), aliskiren (REN inhibitor), or losartan $\left(\mathrm{AT}_{1}\right.$ receptor blocker) prevented the changes in urinary protein excretion and SBP observed in NFX animals without treatment (Figure 1(b))

\subsection{Effect of RAS Blockade on Plasma Ang II and Ang 1-7 Levels}

Plasma Ang II level was increased 9.7 fold, whereas Ang 1-7 was reduced $\sim 72.9 \%$ in NFX animals compared with SO rats after 60 days of surgery $(p=0.001)$. RAS blockade clearly prevented the increase on Ang II

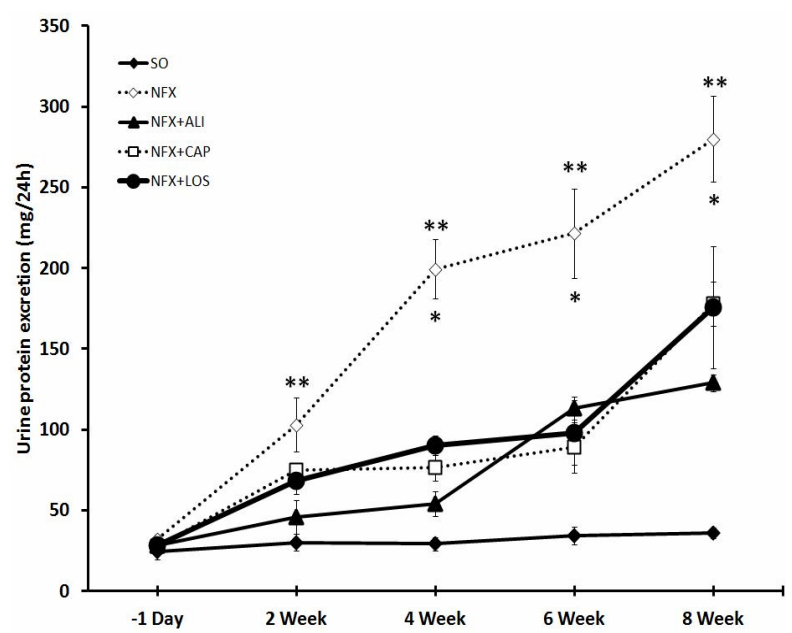

(a)

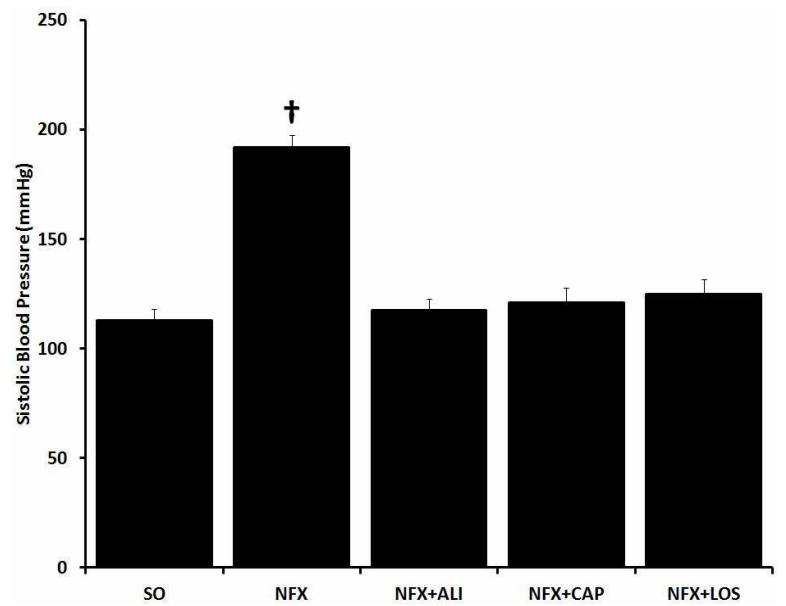

(b)

Figure 1. Effect of renin angiotensin system inhibition on kidney failure. Urinary protein excretion (a), and systolic blood pressure (b) were evaluated in sham operated rats (SO), 5/6 nephrectomized (NFX) rats, 5/6 nephrectomized rats treated with a renin inhibitor (NFX + ALI), angiotensin converting enzyme inhibitor (NFX $+\mathrm{CAP})$, and $\mathrm{AT}_{1}$ receptor blocker $(\mathrm{NFX}+\mathrm{LOS})$. Urinary protein excretion was evaluated at week $2,4,6$, and 8 after surgery $\left({ }^{*} \mathrm{p}<0.5 \mathrm{NFX}\right.$ vs. NFX + CAP, NFX + LOS, ${ }^{* *} \mathrm{p}<0.5 \mathrm{NFX}$ vs. NFX + ALI). Blood pressure was measured 60 days post $5 / 6$ nephrectomy $\left({ }^{\dagger} \mathrm{p}<0.5 \mathrm{SO}\right.$ vs. NFX). Data are presented as mean $\pm \operatorname{SEM}(n=5)$.

caused by $5 / 6$ nephrectomy (Figure 2(a)). However, the Ang 1-7 reduction presented in NFX rats was prevented by $\mathrm{ACE}$ inhibition or $\mathrm{AT}_{1}$ receptor blockade and was not affected by REN inhibition (Figure 2(b)).

\subsection{Effect on Renal RAS mRNA Expression}

The RAS mRNA expression profiles were altered in the remnant kidney from NFX animals compared with SO rats, 60 days after surgery. AGT and (P)RR mRNA expression were increased 1.82 fold $(p=0.023)$ and 2.16 fold $(p=0.008)$ respectively, whereas REN mRNA ex- 


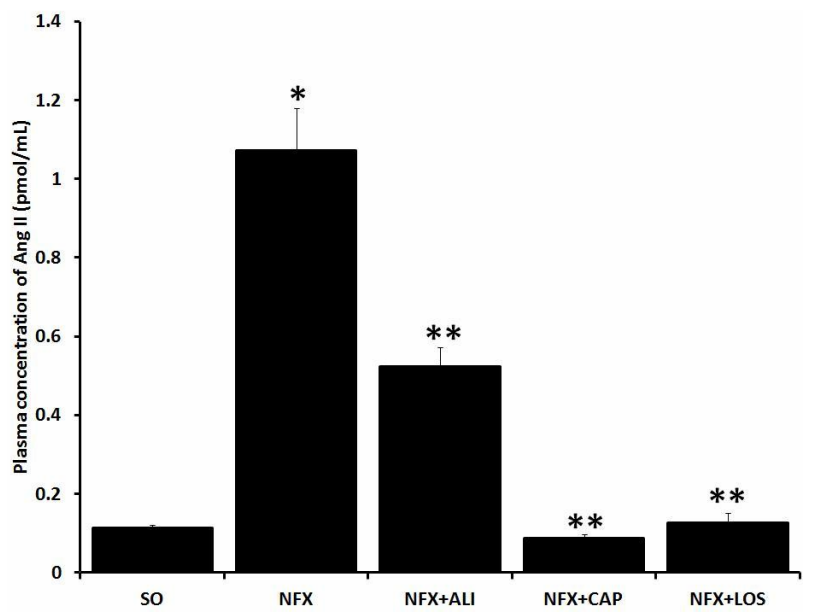

(a)

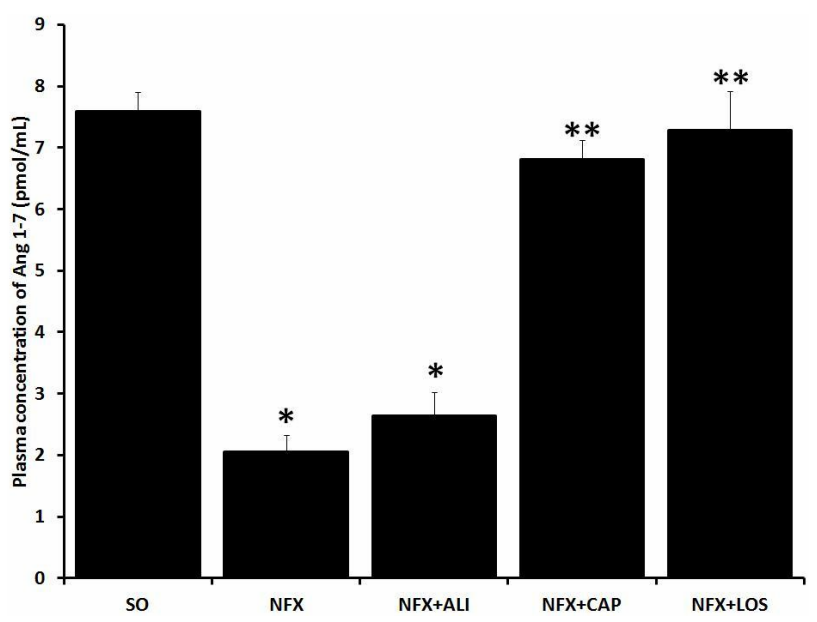

(b)

Figure 2. Effect of renin angiotensin system inhibition on plasma Ang II and Ang 1-7 levels. Plasma Ang II (a), and Ang 1-7 (b) levels were evaluated in sham operated rats (SO), 5/6 nephrectomized (NFX) rats, 5/6 nephrectomized rats treated with a renin inhibitor (NFX $+\mathrm{ALI})$, angiotensin converting enzyme inhibitor (NFX $+\mathrm{CAP}$ ), and $\mathrm{AT}_{1}$ receptor blocker (NFX + LOS). Ang II and Ang 1-7 were measured 60 days after $5 / 6$ nephrectomy, treatment started day 1 after surgery. Each bar represents the mean $\pm \operatorname{SEM}(\mathrm{n}=5) .{ }^{*} \mathrm{p}<0.5$ vs. SO, ${ }^{* *} \mathrm{p}<0.5$ vs. NFX.

pression was reduced $82.9 \%(\mathrm{p}<0.05)$. ACE mRNA expression was not affected by the $5 / 6$ nephrectomy. RAS blockade also modified the renal RAS mRNA expression. Inhibition of REN (aliskiren), and ACE (captopril), or $\mathrm{AT}_{1}$ receptor blockade (losartan) in NFX rats reduced the mRNA expression of (P)RR, AGT, and ACE $(p<0.05)$ whereas REN mRNA expression was increased compared with NFX rats without treatment $(\mathrm{p}<$ 0.05) (Figure 3).

\section{DISCUSSION}

The 5/6 nephrectomy model is a classic animal repre- sentation of Ang II-dependent progressive renal impairment and hypertension. We demonstrated, in this study, that 5/6 nephrectomy modifies plasma Ang II and Ang 1-7 concentrations, as well as renal RAS mRNA expression. Moreover, RAS blockade was associated with restoration of plasma Ang 11 and Ang 1-7 concentrations along with changes in renal RAS mRNA expression. Animals that underwent 5/6 nephrectomy developed high blood pressure and proteinuria after 60 days in comparison with the SO animals. As expected, RAS blockade with either $\mathrm{AT}_{1}$ receptor blocker (losartan), ACE (captopril) or renin (aliskiren) inhibitors was associated with normalization of SBP values after 60 days treatment post nephrectomy. Urine protein excretion, as kidney function indicator, showed that proteinuria in NFX rats was progressively elevated. Additionally, $\mathrm{AT}_{1}$ receptor blockade (losartan) and ACE inhibition (captopril) prevented the increment of urine protein excretion on NFX animals since day 28 after 5/6 nephrectomy. Our findings corroborate previous reports that showed the association of RAS blockade with normalization of blood pressure and kidney damage reduction $[15,18]$. Interestingly, decreased urine protein excretion was observed from day 14 after nephrectomy in animals treated with the REN inhibitor aliskiren, suggesting an early effect on kidney protection. REN inhibition in NFX animals showed a sustained reduction on proteinuria through this study. This efficient renoprotective effect by direct renin inhibition has been also reported by others [19].

Plasma Ang II was elevated in NFX animals whereas Ang 1-7 decreased 72.9\% compared with SO rats. Previous reports that support our data have shown similar changes during renal damage [20]. Moreover, RAS blockade with captopril or losartan showed significant reduction in plasma Ang II and this was associated with elevation of Ang 1-7, further supporting RAS-dependent effect on the 5/6 nephrectomy kidney failure model. Coincidently, other studies have demonstrated elevation on the Ang 1-7 circulating levels produced by ACE inhibitors or $\mathrm{AT}_{1}$ receptor blockers [21,22]. However, direct $\mathrm{REN}$ inhibition with aliskiren did not increase plasma Ang 1-7, probably due to the synthesis inhibition of Ang 1-7 precursors, Ang I and Ang II. Similarly, Rusai et al. reported reduced serum Ang II and Ang 1-7 in a chronic allograft dysfunction model treated with aliskiren [23]. 5/6 nephrectomy increased AGT and (P)RRmRNA expression in the remnant kidney, while REN mRNA was decreased. Plasma Ang II has been suggested as responsible for the regulation of RAS genes expression. Up regulation of AGT mRNA expression by Ang II is caused by a positive feedback on the AGT gene and this feedback is in turn balanced by Ang II negative feedback on REN $[2,24]$. Our data support the idea that increased Ang II concentration is associated with mRNA regulation of 


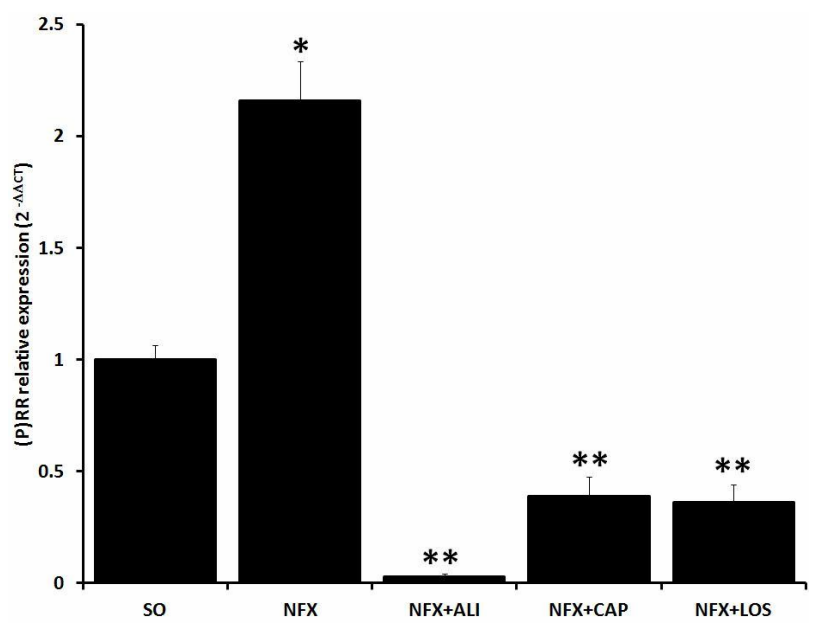

(a)

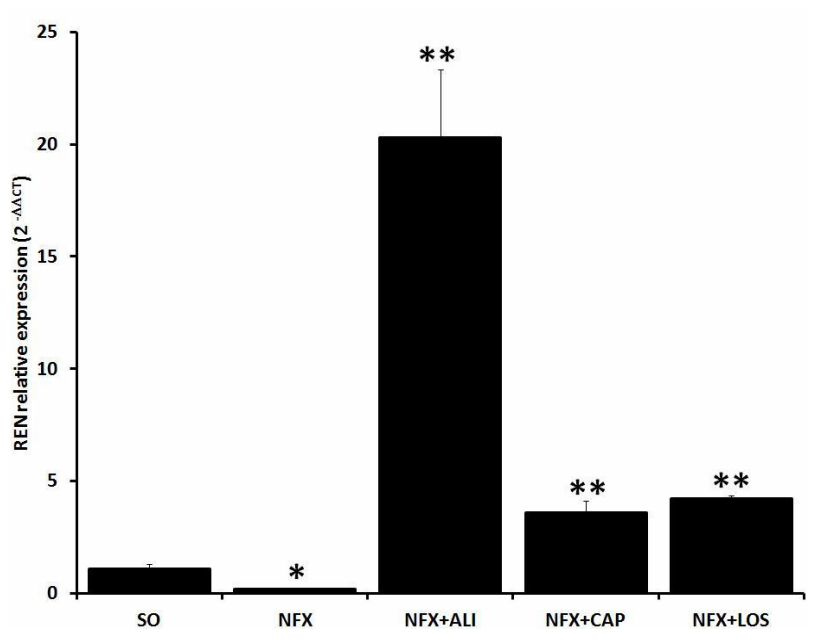

(c)

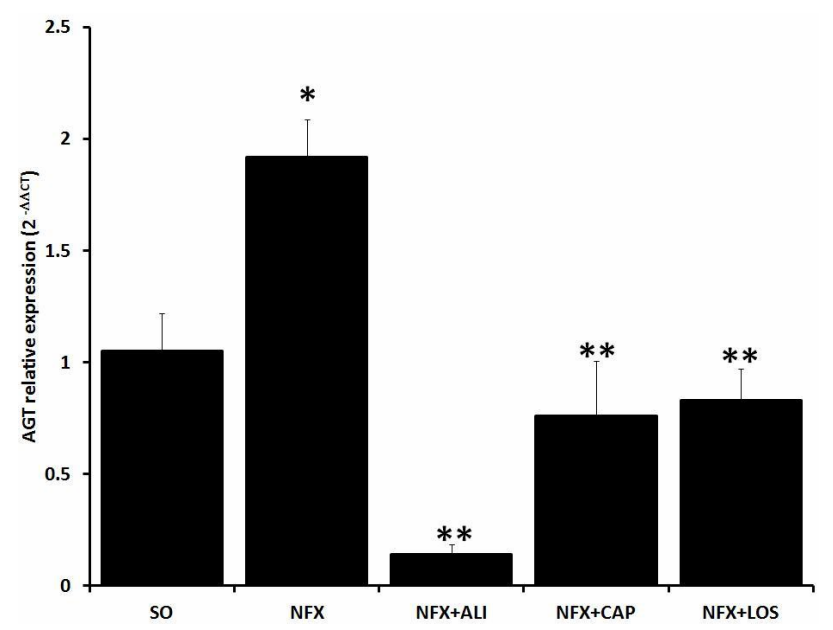

(b)

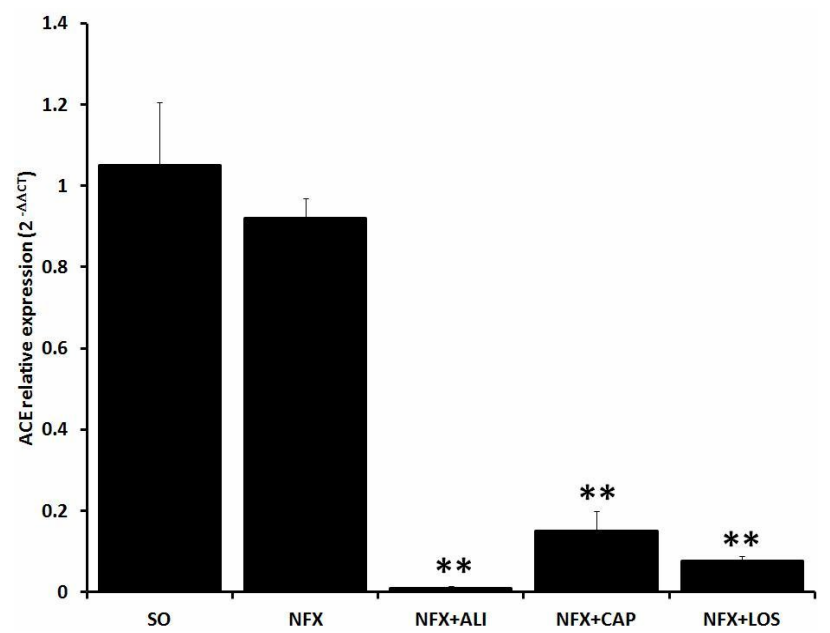

(d)

Figure 3. Effect of renin angiotensin system inhibition on renal renin angiotensin system mRNA expression. Kidney mRNA expression levels of (P)RR (a), AGT (b), REN (c), and ACE (d) were evaluated in sham operated rats (SO), 5/6 nephrectomized (NFX) rats, $5 / 6$ nephrectomized rats treated with a renin inhibitor (NFX $+\mathrm{ALI})$, angiotensin converting enzyme inhibitor (NFX $+\mathrm{CAP})$, and $\mathrm{AT}{ }_{1}$ receptor blocker (NFX + LOS). Kidney tissue was obtained 60 days after 5/6 nephrectomy. Treatment started day 1 after surgery. Expression levels of each mRNA were normalized with the expression level of the endogenous gene, 18S rRNA. Each bar represents the mean $\pm \operatorname{SEM}(\mathrm{n}=5) .{ }^{*} \mathrm{p}<0.5$ vs. SO sham and ${ }^{* *} \mathrm{p}<0.5$ vs. NFX.

RAS genes. Additionally, depletion of Ang II with ACE inhibitors, $\mathrm{AT}_{1}$ receptor blockers, or REN inhibitors modify renal RAS mRNA expression and further corroborate that Ang II levels are critical in the regulation of RAS mRNA intermediaries. The alterations in Ang 1-7 concentration in NFX rats suggest that Ang 1-7 may play a major role in the regulation of RAS mRNA expression during renal damage development. Other studies have shown the impact of Ang 1-7 on RAS genes expression in the kidney $[25,26]$. Our data might suggest that reduced Ang 1-7 levels could be associated with RAS over-activation via increased renal genes expression, whereas restoration of the Ang 1-7 by ACE inhibition, $\mathrm{AT}_{1}$ receptor blockade, and REN inhibition may participate in down-activation by regulation of RAS mRNA genes. Thus, it is possible that the two main RAS active peptides, Ang II and Ang 1-7 play an important role in the RAS gene mRNA autoregulation, Ang II stimulates and Ang 1-7 inhibits. Indeed, it has been reported that Ang 1-7 may antagonize the actions of Ang II especially in situations of an overactive RAS [5,25]. This heptapeptide interacts with the $\mathrm{G}$ protein-coupled recaptor Mas and exerts many actions that counteract those elicited by Ang II eg, vasodilation, improved renal blood flow, and enhanced pressure natriuresis. It also has antiproliferative actions on vascular smooth muscle and on cardiac myocytes stimulates nitric oxide and prostaglandin release [27]. Therefore, the net action of RAS in the long-term regulation of blood pressure and kidney function may depend on the balance between the effects of 
Ang II and Ang 1-7 [28].

All these data lead us to conclude that renal regulation of RAS mRNA expression is related with the Ang II/Ang 1-7 balance and that pharmacological blockade of the RAS pathway can be also associated with the regulation of renal RAS genes expression. These findings expand the view of RAS interactions within its own components and may contribute to elucidate new therapeutic responses.

\section{ACKNOWLEDGEMENTS}

This work was supported by the Mexican Council of Science and Technology (CONACYT), Research grant 81359 to Dr. Escalante and a CONACYT fellowship to Erika Cruz. We thank M.S. Azzael Hernández-Morán for technical assistance.

\section{REFERENCES}

[1] Liang, P., Jones, C.A., Bisgrove, B.W., et al. (2004) Genomic characterization and expression analysis of the first non mammalian renin genes from zebrafish and pufferfish. Physiological Genomics, 16, 314-322. doi:10.1152/physiolgenomics.00012.2003

[2] Kobori, H., Nangaku, M., Navar, L.G. and Nishiyama, A. (2007) The intrarenal renin angiotensin system: From physiology to the pathobiology of hypertension and kidney disease. Pharmacological Reviews, 59, 251-287. doi:10.1124/pr.59.3.3

[3] Carey, R.M. and Siragy, H.M. (2003) Newly recognized components of the renin-angiotensin system: Potential roles in cardiovascular and renal regulation. Endocrine Reviews, 24, 261-271. doi:10.1210/er.2003-0001

[4] Ribeiro-Oliveira Jr, A., Nogueira, A.I., Pereira, R.M., Boas, W.W., Dos Santos, R.A. and Simões e Silva, A.C. (2008) The renin-angiotensin system and diabetes: An update. Journal of Vascular Health and Risk Management, 4, 787-803.

[5] Santos, R.A., Ferreira, A.J. and Simões e Silva, A.C. (2008) Recent advances in the angiotensin-converting enzyme 2-angiotensin (1-7)-Mas axis. Experimental Physiology, 93, 519-527.

doi:10.1113/expphysiol.2008.042002

[6] Schefe, J.H., Menk, M., Reinemund, J., Effertz, K., Hobbs, R.M., Pandolfi, P.P., Ruiz, P., Unger, T. and Funke-Kaiser, H. (2006) A novel signal transduction cascade involving direct physical interaction of the renin/ prorenin receptor with the transcription factor promyelocytic zinc finger protein. Circulation Research, 99, 1355-1366. doi:10.1161/01.RES.0000251700.00994.0d

[7] Brasier, A.R., Jamaluddin, M., Han, Y., Patterson, C. and Runge, M.S. (2000) Angiotensin II induces gene transcription through cell-type-dependent effects on the nuclear factor-kappaB (NF-kappaB) transcription factor. Molecular and Cellular Biochemistry, 212, 155-169. doi:10.1023/A:1007133710837

[8] Kang, J.J., Toma, I., Sipos, A., Meer, E.J., Vargas, S.L. and Peti-Peterdi, J. (2008) The collecting duct is the major source of prorenin in diabetes. Hypertension, 51,
1597-1604. doi:10.1161/HYPERTENSIONAHA.107.107268

[9] Prieto-Carrasquero, M.C., Kobori, H., Ozawa, Y., Gutierrez, A., Seth, D. and Navar, L.G. (2005) AT1 receptor-mediated enhancement of collecting duct renin in angiotensin II-dependent hypertensive rats. Renal Physiology: American Journal of Physiology, 289, F632-F637.

[10] Prieto-Carrasquero, M.C., Botros, F.T., Pagan, J., et al. (2008) Collecting duct renin is upregulated in both kidneys of 2-kidney, 1-clip goldblatt hypertensive rats. Hypertension, 51, 1590-1596. doi:10.1161/HYPERTENSIONAHA.108.110916

[11] Krskova, K., Filipcik, P., Zilka, N., et al. (2011) Angiotensinogen and angiotensin-converting enzyme mRNA decrease and AT1 receptor mRNA and protein increase in epididymal fat tissue accompany age-induced elevation of adiposity and reductions in expression of GLUT4 and peroxisome proliferator-activated receptor (PPAR $\gamma)$. Journal of Physiology and Pharmacology, 62, 403-410.

[12] Arellano-Mendoza, M.G., Vargas-Robles, H., Del ValleMondragon, L., Rios, A. and Escalante, B. (2011) Prevention of renal injury and endothelial dysfunction by chronic L-arginine and antioxidant treatment. Renal Failure, 33, 47-53. doi:10.3109/0886022X.2010.541583

[13] Bradford, M.M. (1976) A rapid and sensitive method for the quantitation of microgram quantities of protein utilizing the principle of protein-dye-binding. Analytical Biochemistry, 72, 248-254. doi:10.1016/0003-2697(76)90527-3

[14] Cervantes-Pérez, L.G., Ibarra-Lara, M.L., Rubio, M.E., et al. (2010) Effect of clofibrate on vascular reactivity in a model of high blood pressure secondary to aortic coarctation. Pharmacological Reports, 62, 874-882.

[15] Tenorio-López, F.A., Zarco-Olvera, G., Sánchez-Mendoza, A., Rosas-Peralta, M., Pastelín-Hernández, G. and del Valle-Mondragón, L. (2010) Simultaneous determination of angiotensins II and 1-7 by capillary zone electrophoresis in plasma and urine from hypertensive rats. Talanta, 80, 1702-1712. doi:10.1016/j.talanta.2009.10.010

[16] Livak, K.J. and Schmittgen, T.D. (2001) Analysis of relative gene expression data using real-time quantitative PCR and the 2(-Delta Delta C(T)) Method. Methods, 25, 402-408. doi:10.1006/meth.2001.1262

[17] Sanchez, P.L., Salgado, L.M., Ferreri, N.R. and Escalante, B. (1999) Effect of cyclooxygenase-2 inhibition on renal function after renal ablation. Hypertension, 34, 848-853. doi:10.1161/01.HYP.34.4.848

[18] Rakusan, D., Kujal, P., Kramer, H.J., et al. (2010) Persistent antihypertensive effect of Aliskiren is accompanied by reduced proteinuria and normalization of glomerular area in Ren-2 transgenic rats. American Journal of Physiology-Renal Physiology, 299, F758-F766. doi:10.1152/ajprenal.00259.2010

[19] Gross, O., Girgert, R., Rubel, D., Temme, J., Theissen, S. and Müller, G.A. (2011) Renal protective effects of Aliskiren beyond its antihypertensive property in a mouse model of progressive fibrosis. American Journal of $\mathrm{Hy}$ pertension, 24, 355-361. doi:10.1038/ajh.2010.231 
[20] Velkoska, E., Dean, R.G., Burchill, L., Levidiotis, V. and Burrell, L.M. (2010) Reduction in renal ACE2 expression in subtotal nephrectomy in rats is ameliorated with ACE inhibition. Clinical Science (Lond)., 118, 269-279. doi:10.1042/CS20090318

[21] Iyer, S.N., Yamada, K., Diz, D.I., Ferrario, C.M. and Chappell, M.C. (2000) Evidence that prostaglandins mediate the antihypertensive actions of angiotensin-(1-7) during chronic blockade of the renin-angiotensin system. Journal of Cardiovascular Pharmacology, 36, 109-117. doi:10.1097/00005344-200007000-00015

[22] Nakamura, S., Averill, D.B., Chappell, M.C., Diz, D.I., Brosnihan, K.B. and Ferrario, C.M. (2003) Angiotensin receptors contribute to blood pressure homeostasis in salt-depleted SHR. American Journal of PhysiologyRegulatory, Integrative and Comparative Physiology, 284, R164-R173.

[23] Rusai, K., Schmaderer, C., Hermans, J.J., Lutz, J., Heemann, U. and Baumann, M. (2011) Direct renin inhibition in a rat model of chronic allograft injury. Transplantation, 92, 999-1004.

[24] Hirose, T., Mori, N., Totsune, K., Morimoto, R., Maejima, T., Kawamura, T., Metoki, H., Asayama, K., Kikuya, M.,
Ohkubo, T., Kohzuki, M., Takahashi, K. and Imai, Y (2010) Increased expression of (pro)renin receptor in the remnant kidneys of 5/6 nephrectomized rats. Regulatory Peptides, 8, 93-99. doi:10.1016/j.regpep.2009.11.006

[25] da Silveira, K.D., Pompermayer Bosco, K.S., et al. (2010) ACE2-angiotensin-(1-7)-Mas axis in renal ischaemia/reperfusion injury in rats. Clinical Science (Lond), 119, 385-394. doi:10.1042/CS20090554

[26] Dilauro, M., Zimpelmann, J., Robertson, S.J., Genest, D. and Burns, K.D. (2010) Effect of ACE2 and angiotensin(1-7) in a mouse model of early chronic kidney disease. American Journal of Physiology-Renal Physiology, 298, F1523-F1532. doi:10.1152/ajprenal.00426.2009

[27] Tallant, E.A., Ferrario, C.M. and Gallagher, P.E. (2005) Angiotensin-(1-7) inhibits growth of cardiac myocytes through activation of the mas receptor. American Journal of Physiology Heart and Circulatory Physiology, 289, H1560-H1566. doi:10.1152/ajpheart.00941.2004

[28] Pinheiro, S.V. and Simões e Silva, A.C. (2012) Angiotensin converting enzyme 2, Angiotensin-(1-7), and receptor MAS axis in the kidney. International Journal of Hypertension, 2012, 414128. doi:10.1155/2012/414128 